\title{
Antena Fraktal Koch dengan Catuan EMC pada UHF untuk Aplikasi Televisi Digital Terestrial
}

\section{Koch Fractal Antenna at UHF Band Using EMC Feeding for Digital Terrestrial Television Applications}

\author{
Yuyu Wahyu ${ }^{a}$,, Ukhty Syakirotunnikmah ${ }^{b}$, Heroe Wijantob $^{b}$ \\ Yana Taryana ${ }^{\mathrm{a}}$, Arie Setiawan ${ }^{\mathrm{a}}$ \\ ${ }^{a}$ Pusat Penelitian Elektronika dan Telekomunikasi, Lembaga Ilmu Pengetahuan Indonesia. \\ Komp LIPI Gd 20, Jl Sangkuriang 21/54D, Bandung 40135, Indonesia \\ ${ }^{b}$ Jurusan Teknik Elektro, Fakultas Teknik, Universitas Telkom, \\ Jl. Telekomunikasi Terusan Buah Batu Bandung 40257, Indonesia
}

\begin{abstract}
Abstrak
Televisi merupakan teknologi yang sudah ada sejak beberapa dekade yang lalu. Televisi kini mengalami perkembangan yang awalnya menggunakan modulasi analog, dewasa ini berkembang menggunakan modulasi digital yang harus diimbangi dengan perangkat antena yang handal. Dilatarbelakangi oleh penelitian sebelumnya, maka pada paper ini akan dirancang antena dengan bandwidth yang lebih lebar agar sesuai dengan rekomendasi dari KOMINFO. Pada paper ini, diajukan rancangan antena mikrostrip fraktal Koch iterasi kedua dengan teknik slot pada bagian groundplane-nya dengan pencatuan proximity melalui teknik EMC (electromagnetically coupled) menggunakan bahan material substrat FR4-epoxy dengan konstanta dielektrik bernilai 4,2 pada frekuensi $586 \mathrm{MHz}$. Perancangan dan simulasi dilakukan dengan menggunakan simulator perancangan antena berbasis Finite Integration Technique (FIT). Berdasarkan simulasi dan analisis yang telah dilakukan, menunjukkan bahwa dengan menggabungkan antara teknik pencatuan EMC dan fraktal Koch yang dimodifikasi menjadi slot pada bagian groundplane mampu meningkatkan bandwidth antenna dan didapatkan bandwidth pada VSWR $\leq 1,8$ sebesar 228,6 MHz, gain pengukuran $2,09 \mathrm{~dB}$, pola radiasi bidireksional dan polarisasi elips horizontal.
\end{abstract}

Kata kunci: mikrostrip, fraktal Koch, proximity, EMC, televisi digital terrestrial.

\section{Abstract}

Television is a technology that has been existed since several decades ago. It has advanced from using analogue modulation into using digital modulation that must be balanced with a reliable antenna device. Hence, initiated from the last studies, this research focussed on a large bandwidth antenna for satisfying digital television bandwidth specified by KOMINFO. In this paper, a design of second iteration Koch fractal microstrip antenna is proposed with slotted technique on its groundplane by the proximity feeding applied EMC (electromagnetically coupled) technique by using FR4-epoxy as its substrate material with 4.2 of the dielectric constant and $586 \mathrm{Mhz}$ of the frequency. The modelling and simulation process has been done through antenna design simulator based on Finite Integration Technique (FIT). The results have presented that by combining EMC feeding and modified Koch fractal as slotted on the groundplane, the technique led to bandwidth improvement. The results have also shown that antenna obtained a bandwidth of $228.6 \mathrm{MHz}$ with VSWR $\leq 1.8$, a measured gain of $2.09 \mathrm{~dB}$, and bidirectional radiation pattern and horizontal ellips polarization.

Keywords: microstrip, Koch fractal, proximity, EMC, digital terrestrial television.

I.

\section{Pendahuluan}

Dewasa ini perkembangan teknologi siaran di bidang televisi berkembang dengan pesat. Selama ini sistem siaran yang dipakai adalah sistem siaran analog yang bekerja pada frekuensi 470-806 MHz. Seiring dengan perkembangan teknologi, sistem siaran televisi mulai digunkan sistem siaran digital. Perubahan sistem ini berdampak terhadap perubahan alokasi frekuensi penyiaran televisi karena menurut rekomendasi dari KOMINFO, disebutkan bahwa alokasi frekuensi untuk

\footnotetext{
* Corresponding Author.

Email: yuyuwahyusr@gmail.com

Received: April 13, 2015; Revised: April 24, 2015

Accepted: May 7, 2015

Published: June 30, 2015

(c) 2015 PPET - LIPI

doi : $10.14203 /$ jet.v15.1-5
}

teknologi televisi digital terrestrial ada pada frekuensi 478-694 MHz. Berdasarkan rekomendasi tersebut maka bandwidth yang dibutuhkan untuk televisi digital terrestrial sebesar $216 \mathrm{MHz}$.

Untuk memenuhi kebutuhan salah satu perangkat sistem siaran televisi digital, maka telah dilakukan penelitian pada bagian antena. Pada penelitian ini telah dilakukan rancangan antena mikrostrip log periodik dengan patch meander yang berukuran $81,6 \times 50,94 \mathrm{~mm}$ [1]. Antena ini dirancang pada frekuensi kerja $700 \mathrm{MHz}$ dan menghasilkan bandwidth sebesar $41 \mathrm{MHz}$. Bandwidth yang dihasilkan masih belum memenuhi kebutuhan standar sistem siaran televisi digital. Oleh karena itu untuk mengembangkan penelitian tersebut, perlu digunakan teknik tertentu yang mampu menghasilkan bandwidth yang lebih lebar dan sesuai dengan rekomendasi dari KOMINFO. 
Perbaikan bandwidth dapat dilakukan melalui pemilihan antena jenis fraktal Koch. Pada proses perancangannya dilakukan beberapa iterasi untuk menghasilkan performansi yang dapat memenuhi standar kebutuhan. Berdasarkan hasil iterasi [2], maka iterasi fraktal Koch yang menghasilkan performansi cukup baik terjadi pada iterasi-2. Karena pada peningkatan iterasi-0 hingga iterasi-2 menunjukkan bahwa frekuensi kerja yang dihasilkan semakin turun sedangkan pada iterasi-2 menuju iterasi-3 menunjukkan frekuensi kerja yang semakin meningkat. Karena antena yang dibutuhkan untuk aplikasi televisi digital terrestrial ada pada frekuensi rendah maka digunakan fraktal Koch iterasi-2.

Berdasarkan beberapa pertimbangan tersebut, dalam paper ini diusulkan antena fraktal koch dengan catuan EMC pada UHF untuk aplikasi televisi digital terestrial.

\section{Struktur Dasar}

\section{A. Fraktal Koch}

Bentuk fraktal adalah bentuk geometri yang dapat difragmentasi atau dibagi-bagi menjadi bagian yang lebih kecil karena apabila hasil pembagian diperbesar maka akan terbentuk dimensi yang mirip dengan bentuk aslinya.

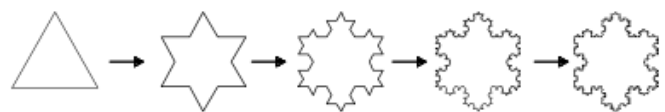

Gambar 1. Proses Iterasi Fraktal Koch [3]

Gambar 1 menunjukkan proses iterasi geometri fraktal Koch mulai dari iterasi-0 sampai iterasi yang lebih kecil. Iterasi-0 merupakan inisiator dengan bentuk segitiga sama sisi.

Antena mikrostrip fraktal dapat digunakan untuk tujuan mereduksi antena, menjadikan antena bersifat multiband hanya dengan menggunakan sebuah antena dan memiliki impedansi input yang baik. Antena fraktal ini memiliki bentuk fisik yang kompleks sesuai dengan hasil iterasinya sehingga dalam merancang model antena ini membutuhkan perhitungan matematis yang teliti [3].

\section{B. EMC (Electromagetically Coupled)}

EMC (electromagetically coupled) merupakan teknik pencatuan tidak langsung yaitu dengan menggunakan dua lapisan substrat, feed line akan diletakkan di antara kedua substrat. Sehingga letak patch berada di atas dua buah substrat [4]. Gambar 2 merupakan konfigurasi bentuk mikrostrip catuan proximity.

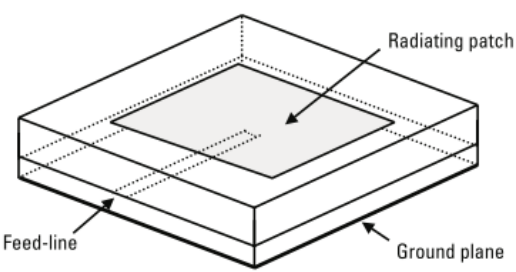

Gambar 2. Electromagtically Coupled [5].
Perancangan dan Realisasi

Proses perancangan dilakukan dengan menggunkanan perangkat lunak simulator perancangan antena CST berbasis Finite Integration Technique (FIT). Perangkat lunak ini dapat memberikan nilai dimensi optimal pada setiap iterasi. Hasil simulasi yang paling optimal kemudian direalisasikan dengan menggunakan bahan material substrat FR4 epoxy yang memiliki konstanta dielektrik 4,2 pada frekuensi 586 $\mathrm{MHz}$ dan pada bagian konduktornya digunakan bahan tembaga dengan ketebalan 0,035 $\mathrm{mm}$.

\section{A. Perancangan dan Simulasi}

Langkah-langkah perancangan antena ditunjukkan pada Gambar 3 sebagai berikut:

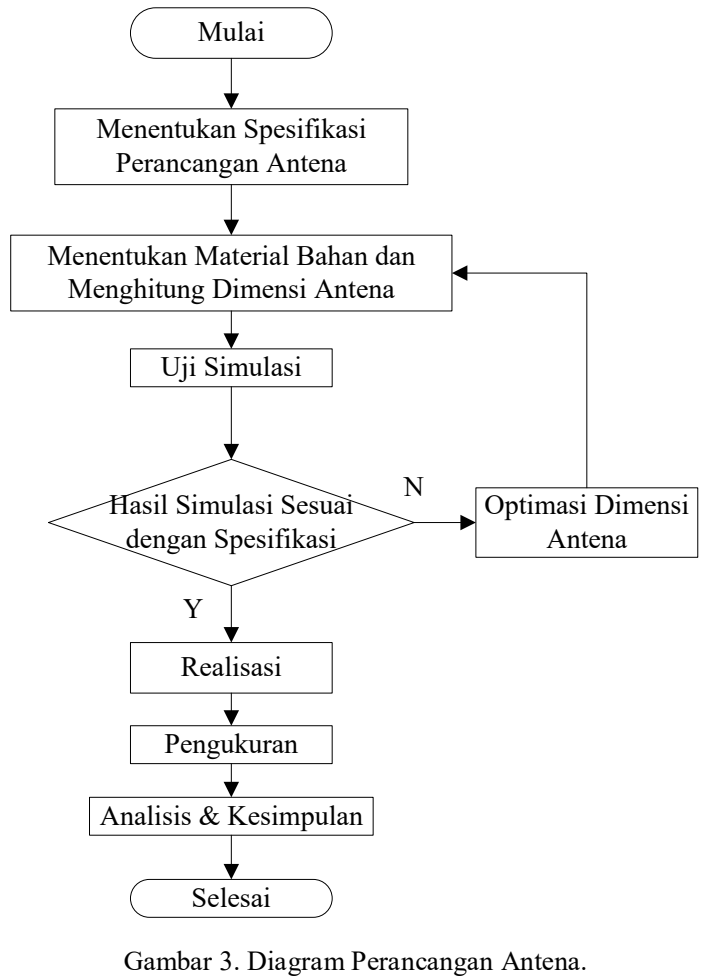

\section{B. Model Perancangan}

Proses perancangan diawali dengan menentukan spesifikasi bentuk antena dan parameter-parameter yang diinginkan, seperti frekuensi kerja, bandwidth, polarisasi, pola radiasi dan gain berikut [6], [7],

TABEL 1

SPESIFIKASI ANTENA TELEVISI DIGITAL TERESTRIAL

\begin{tabular}{|l|l|}
\hline \multicolumn{1}{|c|}{ Spesifikasi } & \multicolumn{1}{c|}{ Keterangan } \\
\hline Frekuensi televisi digital terrestrial & $(478-694) \mathrm{MHz}$ \\
\hline Frekuensi kerja & $586 \mathrm{MHz}$ \\
\hline Bandwidht & $216 \mathrm{MHz}$ \\
\hline Pola radiasi & Unidireksional \\
\hline Polarisasi & Linier Horizontal \\
\hline VSWR & $\leq 1,8$ \\
\hline Gain & $\geq 6 \mathrm{~dB}$ \\
\hline
\end{tabular}

Setelah ditentukan spesifikasi antena yang tertera pada Tabel 1, kemudian dilakukan perhitungan dimensi mikrostrip, mulai dari substrat, groundplane dan patch. Dimensi tersebut dihasilkan dari perhitungan secara matematis pada frekuensi kerja $586 \mathrm{MHz}$. 
Untuk mendapatkan dimensi fraktal Koch, digunakan persamaan-persamaan berikut [8]:

$$
\begin{aligned}
& \lambda=\frac{c}{f} \\
& h=\frac{\lambda}{4} \\
& l=h\left(\frac{4}{3}\right)^{n}
\end{aligned}
$$

di mana

$h=$ sisi segitiga sama sisi $(\mathrm{m})$,

$\lambda=$ panjang gelombang $(\mathrm{m})$,

$c=$ cepat rambat cahaya $=3 \times 10^{8} \mathrm{~m} / \mathrm{s}$,

$f=$ frekuensi kerja $(\mathrm{Hz})$,

$l=$ panjang sisi saat iterasi, $\mathrm{n}$.

Dengan memasukkan nilai $c=3 \times 10^{8} \mathrm{~m} / \mathrm{s}$ dan frekuensi tengah yang dibutuhkan sebesar $f=5,86 \times$ $10^{8} \mathrm{~Hz}$ serta nilai $n=0$ sebagai inisiator maka dihasilkan panjang sisi segitiga sama sisi (inisiator fraktal Koch) sebesar $128 \mathrm{~mm}$.

Gambar 4 menunjukkan bentuk geometri fraktal Koch iterasi-2, dari gambar tersebut terlihat bahwa panjang sisi segitiga sama sisi sebagai inisiator dinyatakan dengn $l(\mathrm{~mm})$. Sehingga berdasarkan rumus segitiga sama sisi, radius dari inisiator tersebut sebesar $r$ $\approx 74 \mathrm{~mm}$.

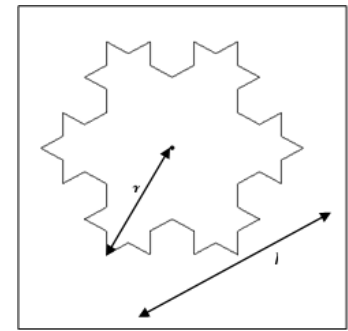

Gambar 4. Geometri Fraktal Koch Iterasi-2.

Proses selanjutnya yaitu menghitung dimensi pencatu dengan menggunakan persamaan microstripline. Impedansi saluran transmisi sebesar 50 $\Omega$ sehingga panjang $(l)$ dan lebar $(w)$ line pencatu sebagai berikut [9]:

$$
\begin{aligned}
& w=\frac{2 h}{\pi}\{B-1-\ln (2 B-1) \\
& +\frac{\varepsilon_{r}-1}{2 \varepsilon_{r}}[\ln (B-1)+0,39 \\
& \left.\left.-\frac{0,61}{\varepsilon_{r}}\right]\right\} \\
& B=\frac{60 \pi^{2}}{Z_{0} \sqrt{\varepsilon_{r}}}=5,77 \\
& w=\frac{2 \times 1,6}{\pi}\{5,77-1-\ln (2 \times 5,77-1) \\
& +\frac{4,2-1}{2 \times 4,2}[\ln (5,77-1) \\
& \left.\left.+0,39-\frac{0,61}{4,2}\right]\right\} \approx 3,1(\mathrm{~mm}) \\
& \varepsilon_{\text {reff }}=\left(\frac{\varepsilon_{r}+1}{2}\right)+\left(\frac{\varepsilon_{r}-1}{2}\right)\left(\frac{1}{\sqrt{1+12 \frac{h}{w}}}\right) \\
& =3,26
\end{aligned}
$$

$$
\begin{gathered}
\lambda_{g}=\frac{\lambda_{0}}{\sqrt{\varepsilon_{\text {reff }}}}=\frac{\frac{c}{f}}{\sqrt{\varepsilon_{\text {reff }}}}=\frac{\frac{3.10^{8}}{586.10^{6}}}{\sqrt{3,26}}=0,28(\mathrm{~m}) \\
l=\frac{\lambda_{g}}{4}=\frac{0,28}{4}=70(\mathrm{~mm})
\end{gathered}
$$

Dari persamaan di atas dihasilkan panjang pencatu sebesar $l \approx 70(\mathrm{~mm})$ dan lebar pencatu sebesar $w \approx$ 3,1 $(\mathrm{mm})$. Setelah dilakukan simulasi, maka menghasilkan dimensi yang paling optimal dan parameter parameter yang ditunjukkan oleh Gambar 5 dan Tabel 2.

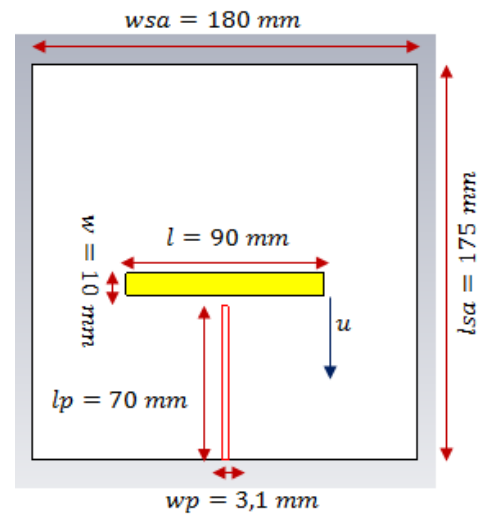

(a)

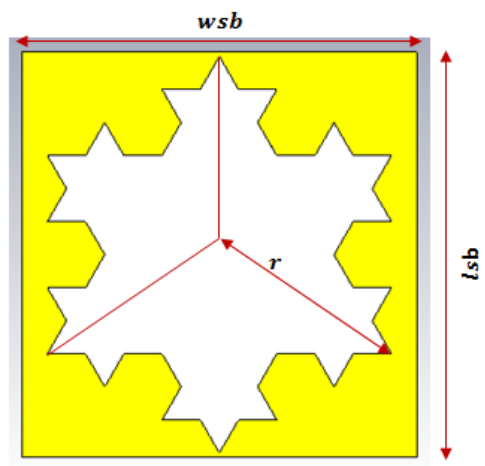

(b)

Gambar 5. Rancangan Antena Setelah Optimasi, (a) Tampak Depan, (b) Tampak Belakang.

TABEL 2

PARAMETER DIMENSI ANTENA

\begin{tabular}{|c|c|c|}
\hline Parameter & Nilai $(\mathbf{m m})$ & Keterangan \\
\hline$h$ & 1,6 & Tebal substrat bawah \\
\hline$h a$ & 1,6 & Tebal substrat atas \\
\hline$l$ & 90 & Panjang patch \\
\hline$l p$ & 85 & panjang pencatu \\
\hline$l s a$ & 175 & Panjang substrat atas \\
\hline$l s b$ & 175 & Panjang substrat bawah \\
\hline$r$ & 88 & Radius \\
\hline$t$ & 0,035 & Tebal patch \\
\hline$u$ & 20 & Pergeseran patch menuju \\
& & tepi bawah \\
\hline$w$ & 10 & Lebar patch \\
\hline$w p$ & 10 & Lebar feed line \\
\hline$w s a$ & 180 & Lebar substrat atas \\
\hline$w s b$ & 180 & Lebar substrat bawah \\
\hline
\end{tabular}


Gambar 6 menunjukkan grafik VSWR hasil simulasi dimana frekuensi yang terlingkupi pada VSWR $\leq 1,8$ yaitu pada 465,63-694,48 $\mathrm{MHz}$ sehingga memiliki bandwidth sebesar 228,85 MHz. Pola radiasi hasil simulasi ditunjukkan pada Gambar 7. Gambar 7 menunjukkan pola radiasi yang dihasillkan pada bidang azimuth dan elevasi berbentuk bidireksional dengan pusatnya pada $0^{\circ}$ dan $180^{\circ}$. Gain yang dihasilkan saat simulasi terlihat pada Gambar 8 sebesar 3,38 dB. Polarisasi bersifat elips dan nilai mainlobe magnitude yang dihasilkan ada di antara $40 \mathrm{~dB}$ sampai tak hingga.

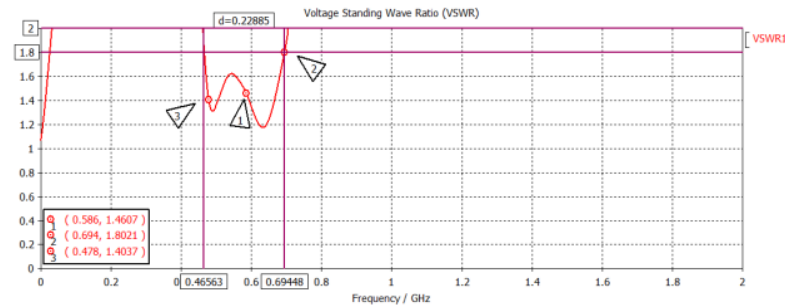

Gambar 6. Grafik VSWR Hasil Simulasi

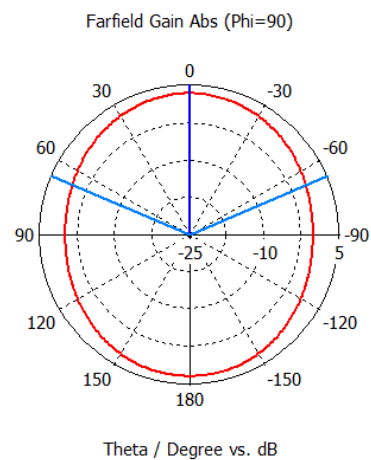

(a)

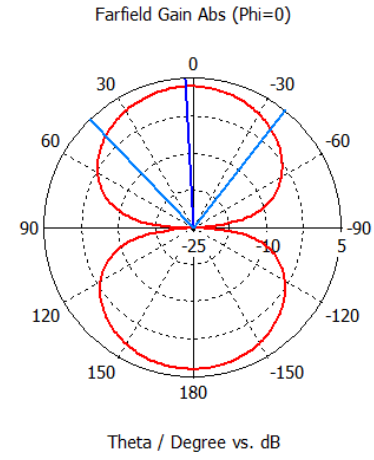

(b)
Gambar 7. Pola Radiasi Hasil Simulasi, (a) Azimuth, (b) Elevasi.

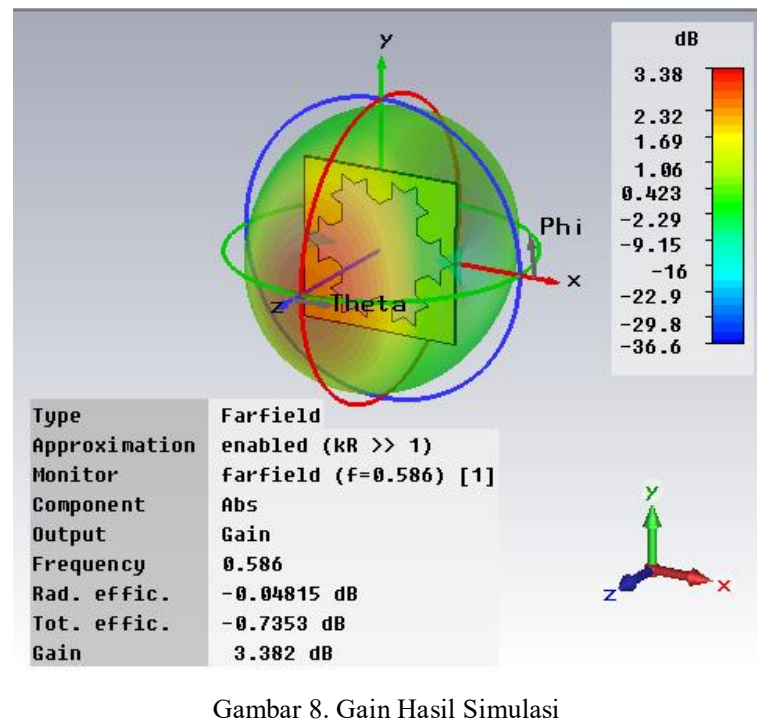

\section{Pengukuran dan Analisis}

Dari hasil simulasi yang paling optimal, kemudian dilakukan proses pabrikasi untuk menghasilkan protipe antena yang ditunjukkan pada Gambar 9. Selanjutnya dilakukan proses pengukuran terhadap prototipe tersebut untuk mendapatkan karakteristik antena yang sebenarnya.
Pengukuran dilakukan pada medan dekat dan medan jauh. Pengukuran medan dekat dimaksudkan untuk melihat lebar bandwidth dan impedan antena. Dari Gambar 10 terlihat bahwa bandwith yang terlingkupi pada VSWR $\leq 1,8$ yaitu $175,125 \mathrm{MHz}$ pada rentang frekuensi 508,9375-684,0625 Mhz dan impedansi antena yang terukur sebesar $(57,280-\mathrm{j} 16,796)$ $\Omega$, sedangkan pengukuran medan jauh dilakukan untuk mengukur pola radiasi, polarisasi dan gain.
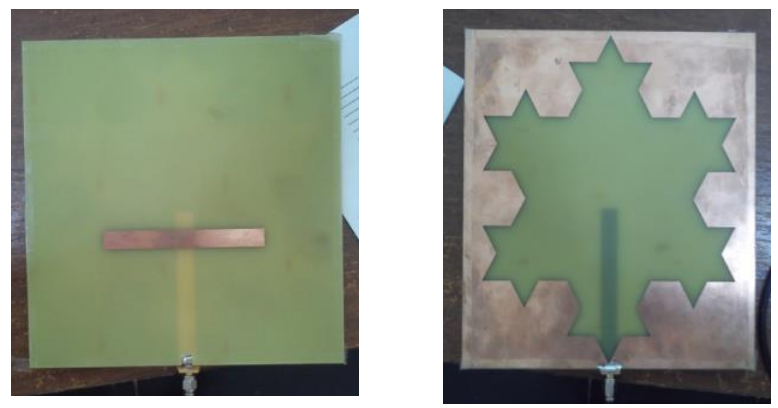

Gambar 9. Prototipe Antena.

Perangkat yang digunakan saat medan jauh yaitu signal generator, spectrum analyzer, dan antena referensi. Antena referensi yang digunakan yaitu dipole dengan gain 2,14 dB dan frekuensi kerja pada 586 MHz. Pada Gambar 10 menunjukkan hasil pengukuran pola radiasi. Pola radiasi secara azimuth (Gambar 11 (a)) terukur bidireksional dengan pancaran utama pada $160^{\circ}$, pola radiasi elevasi (Gambar 11 (1b)) terukur bidireksional dengan pancaran utama $230^{\circ}$ dan polarisasi (Gambar 11 (c)) terhitung secara axial ratio bersifat ellips. Pengukuran gain dilakukan dengan metode dua antena di mana salah satu antena yang digunakan untuk referensi telah diketahui nilai gainnya. Tabel 3 menunjukkan hasil pengukuran gain dengan mengambil sample sebanyak 10 kali. Untuk mendapatkan nilai gain dilakukan perhitungan dengan Persamaan 10. Dari persamaan tersebut gain yang tercapai setelah pengukuran sebesar 2,09 dB.

$$
\begin{gathered}
G_{t}+G_{r}=20 \log \left(\frac{4 \pi R}{\lambda}\right)+10 \log \left(\frac{P_{r}}{P_{t}}\right) \\
2,14+G_{r}=20 \log \left(\frac{4 \pi \times 2}{\frac{3 \times 10^{8}}{586 \times 10^{6}}}\right)+10 \log \left(\frac{1,357 \times 10^{-3}}{1}\right) \\
2,14+G_{r}=33,8-28,67 \\
G_{r}=2,09 d B
\end{gathered}
$$

TABEL 3

DAYA TERIMA PENGUKURAN GAIN

\begin{tabular}{|c|c|}
\hline No. & $\begin{array}{c}\text { Antena Under Test } \\
(\mathbf{d B m})\end{array}$ \\
\hline 1 & -28.82 \\
\hline 2 & -28.98 \\
\hline 3 & -28.73 \\
\hline 4 & -28.77 \\
\hline 5 & -28.73 \\
\hline 6 & -28.88 \\
\hline 7 & -28.72 \\
\hline 8 & -28.29 \\
\hline 9 & -28.69 \\
\hline 10 & -28.13 \\
\hline Daya terima rata & -28.66672217 \\
\hline
\end{tabular}




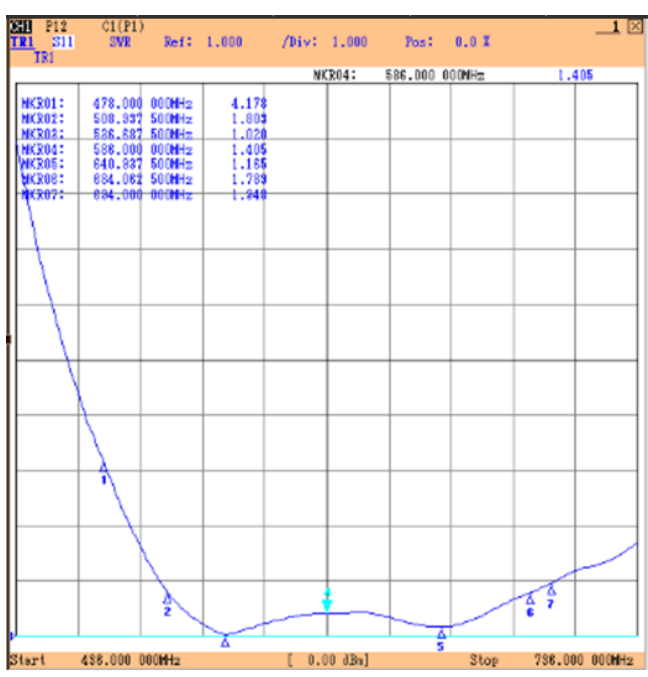

Gambar 10. Hasil Pengukuran Bandwidth VSWR $\leq 1,8$.

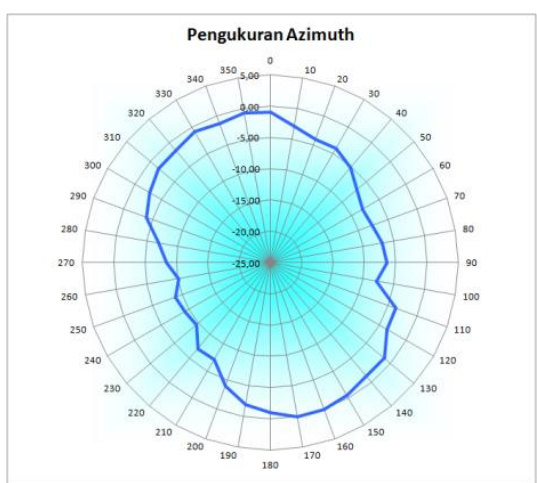

(a)

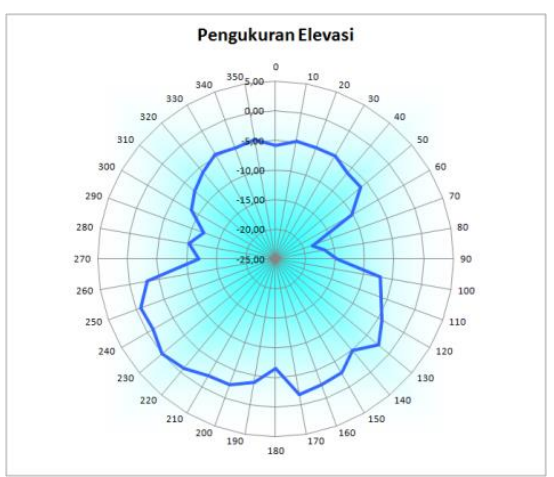

(b)

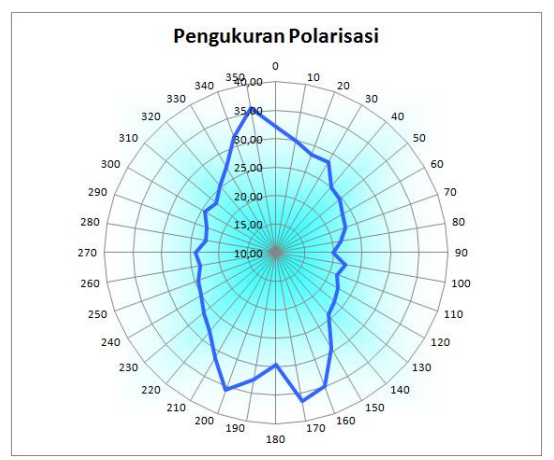

(c)

Gambar 11. Hasil Pengukuran Pola Radiasi, (a) Azimuth, (b) Elevasi, (c) Polarisasi.
Penggunaan slot fraktal Koch pada ground plane mengakibatkan pola radiasi yang dihasilkan bersifat bidireksional, ke depannya hal ini bisa ditanggulangi dengan penggunaan metal reflector pada sisi slot sehingga radiasi bidireksional menjadi unidireksional [10].

\section{KESIMPULAN}

Perancangan antena fraktal Koch dengan menggunakan teknik catuan EMC telah dilakukan. Dari hasil simulasi dan pengukuran didapatkan bandwidth sebesar 228,6 $\mathrm{MHz}$ dengan VSWR $\leq 1,8$, gain pengukuran $2,09 \mathrm{~dB}$, dan pola radiasi bidireksional dan polarisasi elips horizontal. Dengan menggabungkan antara teknik pencatuan EMC dan fraktal Koch yang dimodifikasi menjadi slot pada bagian groundplane menghasilkan bandwidth yang meningkat sebesar 4,27 kali dibandingkan dengan penelitian sebelumnya. Pada bandwidth 228,6 $\mathrm{MHz}$ dengan polarisasi linier horizontal merupakan parameter yang sesuai dengan spesifikasi.

\section{UCAPAN TERIMA KASIH}

Penulis mengucapkan terima kasih kepada PPET LIPI yang telah memfasilitasi pelaksanaan penelitian ini melalui pendanaan DIPA Tematik.

\section{Daftar Pustaka}

[1] H. C. Wicaksono, "Perancangan dan realisasi antena mikrostrip log periodik pada frekuensi $700 \mathrm{MHz}$ untuk aplikasi DVB-T", Skripsi, Universitas Telkom, Bandung, Indonesia, 2013.

[2] Rian Aditia, Y. Christyono, I. Santoso, "Perancangan dan analisis kinerja antena dipole fraktal koch tipe planar pada pita frekuensi UHF televise", Makalah Seminar Tugas Akhir, Jurusan Teknik Elektro, Fakultas Teknik, Universitas Diponegoro, Semarang, Indonesia, 2011.

[3] N. Poprzen and M. Gaćanović. (2015). Fractal antenas: design, characteristics and application. [Online]. Available: http://www.phd.etfbl.net/files/Works_PDF/Poprzen\%20Nemanj $\mathrm{a} \% 20 . p d f$.

[4] R. Garg, P. Bhartia, I. Bahl, and A. Ittipiboon, Microstrip Antena Design Handbook, Norwood, MA-USA: Artech House, Inc., 2001.

[5] G. Kumar and K. P. Ray, Broadband Microstrip Antenas, Norwood, MA-USA: Artech House, Inc., 2003.

[6] D. Setiawan, Alokasi Frekuensi Kebijakan dan Perencanaan Spektrum Indonesia, Jakarta, Indonesia: Departemen Komunikasi dan Informatika, Direktorat Jendral Pos dan Telekomunikasi, 2010.

[7] Y. Wahyu, "Pemancar televisi digital standart DVB-T", PPETLIPI, Bandung, Indonesia, Laporan Penelitian, 2009.

[8] A. Ismahayati, P. J Soh, R. Hadibah, G. A. E Vandenbosch, "Design and analysis of a multiband kotch fractal monopole antenna". In Proceedings of 2011 IEEE International $R F$ and Microwave Conference (RFM 2011, December 2011.

[9] C. A. Balanis, Antena Theory Analysis and Design, 3rd ed., Hoboken, NJ-USA: John Wiley \& Sons, Inc., 2005.

[10] R. N. Simons, Coplanar Waveguide Circuits, Components and System, New York, NY-USA: John Willey and Sons, 2001. 